\title{
Postverdad y discurso intimidatorio en Twitter durante el referéndum catalán del 1-0
}

\section{Post-truth and intimidation on Twitter during Catalan referendum 1-0}

\author{
Víctor Hernández-Santaolalla*, Salomé Sola-Morales* \\ * Universidad de Sevilla, Spain
}

Resumen

\begin{abstract}
La idea de "postverdad" se ha hecho común en el lenguaje mediático, si bien utilizada en ocasiones como sinónimo de mentira y en otras como una tendencia a usar con mayor profusión la argumentación emocional que la racional en la construcción de los mensajes. Al mismo tiempo, existe un creciente uso del discurso intimidatorio en Internet y redes sociales, como una forma -intencionada o no- de acabar con cualquier tipo de debate y, sobre todo, como una forma de comunicación que apuesta por la emocionalidad y renuncia a la racionalidad o la argumentación. Esta propensión se une, al mismo tiempo, a un creciente uso del odio y la intimidación en internet y redes sociales como una forma intencionada o no de acabar con cualquier tipo de debate. En esta línea, el presente artículo analiza los conceptos de postverdad y discurso intimidatorio en el contexto del "proceso catalán" y, en concreto, en el entorno de la votación del 1 de octubre de 2017. Para ello se siguió una metodología cuantitativa, aplicando un análisis de contenido a un total de 573 tuits emitidos entre el 30 de septiembre y el 2 de octubre de 2017. De estos, 150 fueron publicados por trece líderes y portavoces políticos de partidos que contaban con representación en el Congreso de los Diputados y en el Parlament de Catalunya, y el resto eran respuestas de otros usuarios a dichos mensajes. Los resultados corroboran, en consonancia con la idea de postverdad, la tendencia de los políticos a seguir estrategias retóricas basadas en la emoción y los sentimientos. En cuanto a las respuestas de los usuarios, se confirma la tendencia al ataque más que al debate, aunque no se puede confirmar una generalización en el uso de la ofensa y la agresión.
\end{abstract}

Palabras clave: Comunicación política; Catalunya; emoción; cultura del odio; redes sociales.

Abstract

\begin{abstract}
The idea of "post-truth" has become common in media discourse, although sometimes used as a synonym for lying and in others as a tendency to use more emotional argumentation than rational in the construction of the messages. This propensity is linked, at the same time, to a growing use of hate and intimidation on the Internet and social networks sites as an intentional or unintentional mechanism to end any type of debate. At the same time, there is a growing tendency of using intimidation in the Internet and social networks sites as an intentional or unintentional mechanism to end any type of debate. Moreover, this is a form of communication that bets on emotionality and renounces rationality or argumentation. In this line, this article analyzes the concepts of post-truth and intimidatory discourse in the context of the "Catalan process" and, specifically, in the context of voting of October 1st, 2017. For this, a quantitative methodology has been used, applying an analysis of content to a total of 573 tweets issued between September 30th and October 2nd, 2017. Of these, 150 were published by 13 leaders and political parties spokespersons of parties that had representation in the Congress of Deputies and in the Parlament of Catalonia, and the rest were responses to these messages from other users. The results corroborate, in line with the idea of post-truth, the tendency of politicians to follow rhetorical strategies based on the emotion and feelings. Regarding the responses of users, the tendency to the attack more than to the debate is confirmed. However, a generalization in the use of offense and aggression can not be confirmed.
\end{abstract}

Keywords: Political communication; Catalonia; emotion; hateful culture; social media.

Submitted: 29th July 2018

Accepted: 2nd December 2019

Copyright @ 2019 (Víctor Hernández-Santaolalla, Salomé Sola-Morales). Licensed under the Creative Commons AttributionNonCommercial Generic (cc by-nc). Available at http://obs.obercom.pt. 


\section{Introducción}

El término "postverdad" hace alusión a diferentes fenómenos que se vienen dando en la arena política y mediática desde hace más de tres décadas, poniendo en jaque las democracias occidentales. Ya en 1992, Steve Tesich alertó en The Nation, sobre la tendencia o decisión de la sociedad estadounidense de vivir en una sociedad de postverdad, donde reinaba -a su juicio- el gobierno de la mentira (refiriéndose a la Administración de George Bush). Algunos años más tarde, Ralph Keyes (2004) continuó el debate relacionando el concepto con un nuevo periodo histórico que denominó: "era de postverdad". Eric Alterman (2004) lo definió como una forma de gobierno -"presidencia de postverdad"-, mientras que David Roberts (2010) lo vinculó con la política llamándolo "política de la post-verdad", haciendo alusión a los políticos que negaron el cambio climático.

La política de la postverdad podría ser descrita como una forma de hacer política en la que valen más los sentimientos o emociones de la ciudadanía que la argumentación racional (Arrese, 2016; Boczkowski, 2016; González, 20017; Marzal \& Casero Ripollés, 2017; Urmeneta, 2017). En esta línea, no debe olvidarse que sentimientos como la desafección, por ejemplo, motivan la ausencia de confianza, el distanciamiento o la alienación, y terminan repercutiendo en la eficacia política (López-Hermida Russo \& Fierro-Zamora, 2018). De este modo, como algunos autores han advertido, esta tendencia podría entenderse como un virus (Elías, 2017) o un peligro para la democracia (Coughlan, 2017; Valadier, 2017), ya que podría incrementar el populismo, la desconfianza o la apatía de la ciudadanía hacia los partidos o los representantes políticos o, incluso, potenciar otras lacras como la corrupción, todas ellas tendencias que a día de hoy se están dando a lo largo y ancho de los sistemas democráticos occidentales. Como ha expresado Manrique (2016, p. 164): "La 'noble mentira' del gobernante asocia hipocresía y autoengaño, desprecia la libertad y la dignidad públicas, vulnera el espíritu moral y se constituye en instrumento funcional de todos los totalitarismos".

\section{Marco teórico}

\section{El discurso de la mentira contemporáneo: postverdad y fake news}

El debate sobre la mentira no es nada nuevo ni exclusivo de la posmodernidad. Ya en 1873, por ejemplo, en Sobre verdad y mentira en un sentido extramoral, Friederich Nieztsche se refería a las palabras como metáforas que no corresponden en absoluto a las esencias primitivas. Si bien el periodismo informativo contemporáneo ha asentado sus bases sobre la premisa "Facts are sacred, opinions are free", actualmente pareciera que esta clásica expresión se está transformando en su contrario (Arrese, 2016), pues el rumor, el bulo, la mentira y la falsedad manifiesta se están convirtiendo en un ingrediente más del proceder de algunos políticos, periodistas y ciudadanos o usuarios de las redes sociales. Esta tendencia tampoco es ninguna novedad del siglo XXI, pues ya desde hace más de un siglo se reportan casos de publicaciones falsas en los diarios. Es más, el rol de las noticias falsas es una constante y un elemento central en la dinámica de la comunicación política (McNair, 2017). 
No obstante, en la era digital las fake news parecen haber aumentado, pues contribuyen a tendencias políticas y sociales más amplias en las sociedades del actual siglo (Mcnair, 2018). Justamente, para algunos autores este fenómeno expresa una crisis más amplia de confianza en las élites, cuyos miembros están luchando por mantener sus roles tradicionales en nuestras democracias liberales (McNair, 2017). Pero además esta tendencia se ve fomentada por un flujo constante de información, donde "se difuminan las fronteras entre el periodismo y otras formas de comunicación y activismo" (Aguirre Nieto \& Zeta del Pozo, 2017, p. 170); donde la ética periodística es cada vez más cuestionable (Lăzăroiu, 2018) y donde la credibilidad informativa es cuestionada (Vergeer, 2018). La velocidad e inmediatez de algunas plataformas como Twitter o Facebook provocan que las llamadas fake news proliferen y que ni siquiera sean cuestionadas por los lectores que las "retuitean" o comparten a nivel masivo. De esta manera, el sistema mediático se retroalimenta con los bulos publicados en estas redes sociales. Y dado que estos contenidos parecen más conectados con la realidad -ya que muchas veces se nutren de vídeos en directo o de opiniones de ciudadanos a pie-, pueden dar legitimidad a noticias falsas (Alves \& Oliveira, 2016). Es más, según Viner (2016), los algoritmos o filter bubbles (Pariser, 2011) que crea Facebook están diseñados para dar a los usuarios lo que desean y así es más sencillo que confíen en estas noticias que en las publicadas en los medios de comunicación tradicionales, transformando el valor de la información (Marcos Recio, Sánchez Vigil \& Olivera Zaldua, 2017).

\section{Discursos intimidatorios y mensajes de odio en redes sociales}

Al mismo tiempo que las fake news han proliferado en el entorno digital actual donde prima la emoción a la argumentación racional, los discursos intimidatorios parecen haber aumentado y haberse convertido en algo habitual en los foros o espacios de debate virtual. A pesar de que estos discursos son muy longevos (Rowbottom, 2012), "es en sociedades abiertas, en que la libertad de expresión se ha ganado merecidamente un lugar de honor, donde el conflicto entre la libertad de palabra y la protección de los derechos de quienes son objeto de esos discursos ha exigido ponerles un nombre para reconocerlos y poder hacer frente a ese crucial conflicto" (Cortina, 2017, p. 9). Valga indicar que utilizamos el concepto discurso intimidatorio en el sentido epistemológico utilizado por Lopez Muñoz y Capponi (2017), que permite englobar tanto los mensajes del odio (hate speech, discours de la haine, etc.) como las distintas formas de amenazas verbales. Para los investigadores, el discurso intimidatorio se trata de una "práctica discursiva formalmente amplia y heterogénea caracterizada por la intención de potenciar las tensiones existentes entre determinados grupos sociales o demográficos, a través de estrategias que abarcan desde la reafirmación identitaria de pertenencia al grupo dominante hasta la generación de inseguridad o de miedo en el grupo dominado, más que como una mera forma de expresión de la violencia verbal entre individuos" (Lopez Muñoz \& Capponi, 2017, p. 10). En este sentido, el anglosajón hate speech (Waldron, 2012, Whillock \& Slayden, 1995) traducido como discurso del odio en español y considerado por algunos autores confuso y polisémico (Carrillo Donaire, 2017) es entendido aquí como un producto verbal o práctica discursiva (Fernández Smith, 2017) que, por una parte, manifiesta "la emotividad catártica, la 
descalificación simplista y las supercherías de toda índole" (Trejo Delarbre, 2017, p. 8) y, por otra, tiene como finalidad principal la manipulación de las ideas (Casado Velarde, 2008).

El incremento de este fenómeno en el espacio virtual se debe, en gran parte, a que en las últimas décadas el concepto de audiencia se ha visto transformado por completo en el entorno digital. Los tradicionales lectores se han convertido en usuarios o "prosumidores" (Cebrián, 2009; García-Galera \& Valdivia, 2014; Krijnen \& Van Bauwel, 2015), que interactúan entre sí (Navarro, 2009) y participan digitalmente. El debate online genera una mayor flexibilidad que el offline, ya que permite difuminar las fronteras de la libertad de expresión gracias al anonimato (Camps, 2017; Poland, 2016; Reagle, 2015; Reader, 2012; Suler \& Phillips, 2009). No obstante, algunos autores consideran que "son escasamente propicias para suscitar la deliberación pública. Lo que abunda en ellas son la emotividad catártica, la descalificación simplista y las supercherías de toda índole" (Trejo Delarbre, 2017, p. 8). Asimismo, pueden dar lugar a distorsiones generadas por otras prácticas que se dan en el entorno virtual como son el flooding, el trolling, el spamming, el impostoring (Suler \& Phillips, 2009), el online shaming u otras como el llamado derailing o desorientación y reorientación del debate (Poland, 2016).

En este contexto, existe una tendencia en la que los llamados troles o polemistas participan en foros digitales o hacen comentarios en redes sociales como Facebook, Twitter o YouTube -de medios o perfiles contrarios a su ideología- con la única intención de interrumpir la conversación (Herring, Job-Sluder, Sheckler \& Barab, 2002; Torrijos, 2013), rechazar o confrontar las opiniones que en ellos se defienden o sustentan, así como generar discursos del odio o intimidatorios (Cortina, 2017; Montaña, González \& Ariza, 2013). No en vano, en las últimas décadas han proliferado sitios dedicados a la xenofobia y al ciberodio (Banks, 2010; Citron \& Norton, 2011). Estas narrativas "funcionan como alimentador de tensiones previamente existentes entre grupos sociales, actualizándose en situación de enunciación a través de conflictos de interacción entre individuos concretos" (Lopez Muñoz \& Capponi, 2017, p. 12). "El trol es, por tanto, un tipo de usuario más centrado en sí mismo que en la comunidad, a quien escribir comentarios provocadores que reciban muchas respuestas le produce una fuerte sensación de autoafirmación, que puede llegar a ser adictiva" (Fenoll, 2015, p. 181). A pesar de que hay autores que los han definido como individuos reales narcisistas, maquiavélicos y psicópatas (Shachaf \& Hara, 2010) o sádicos (Buckels, Trapnell, \& Paulhus, 2014), no se puede olvidar que, a veces, son perfiles ficticios, creados en masa, para manipular conversaciones digitales (Aguilar, 2017).

En el terreno concreto de la comunicación política, las redes sociales han introducido nuevas dinámicas de conversación y participación en la vida política, al tiempo que han puesto en duda el papel mediador de los medios de comunicación convencionales (Rúas Araújo \& Casero-Ripollés, 2018). Al respecto, es la red social Twitter la que se ha manifestado como el principal punto de encuentro entre agentes políticos y líderes de opinión (Gallardo Paùls \& Enguiz Oliver, 2016, p. 29). En esta línea, diferentes investigaciones se han centrado en el estudio de Twitter en período electoral, prestando una especial atención al uso que los candidatos hacen de dicha red (Christensen, 2013, Enli \& Skogerbø, 2013; Vergeer \& Hermans, 2013; Vergeer, Hermans, \& Sams, 2011); algunas de las cuales han evidenciado su capacidad persuasiva y su potencial en el desarrollo del liderazgo (Said-Hung, Prati \& Cancino-Borbón, 2018; Sola-Morales \& Flores, 2013). Para la ciudadanía, Twitter se convierte a priori en un espacio de debate donde compartir abiertamente sus opiniones (Chopra, 2014), pero también sus frustraciones (Moya Sánchez \& Herrera Damas, 2016), críticas, quejas o insultos. 
Aunque el uso político de Twitter ha sido analizado especialmente en el contexto estadounidense, en los últimos años en España se ha desarrollado un número considerable de trabajos que abordan este tema desde múltiples perspectivas (Fernández Gómez, Hernández-Santaolalla \& Sanz Marcos, 2018), incluyendo el contexto catalán (Pérez-Curiel \& García-Gordillo, 2018). Así, se ha abordado la figura del candidato (Criado, Martínez-Fuentes \& Silván, 2013), de los fans políticos (Hernández-Santaolalla \& Rubio-Hernández, 2017), o de fenómenos como la interacción (Ramos, Fernández Gómez \& Pineda, 2018; Zugasti Azagra \& Pérez González, 2015) o la viralidad (Congosto, 2015). En cuanto al propio debate político generado en Twitter, algunos autores verán la red como una oportunidad para incrementar la "calidad democrática" a partir de la diversificación de voces (Moya Sánchez \& Herrera Damas, 2015, p. 8), mientras que otros afirman que esta funcionaría como una mera "caja de resonancia" (Gruzd \& Roy, 2014), reforzando la polarización ideológica, pues los usuarios harían uso de la exposición selectiva para acercarse a aquellos canales cuyas opiniones ya comparten. En un punto intermedio se encuentran aquellos autores que señalan que dicha polarización dependerá del tema tratado, incrementándose la posibilidad de su aparición cuando se trata de temas especialmente controvertidos (Barberá, Jost, Nagler, Tucker \& Bonneau, 2015; Garimella, Morales, Gionis \& Mathioudakis, 2018).

\section{El proceso catalán}

Las demandas de independencia del pueblo catalán no son nuevas, vienen planteándose desde hace décadas con mayor o menor intensidad, dado que la cohesión nacional de España entre sus autonomías siempre ha sido débil (Colomer, 2018). No obstante, desde el inicio de la crisis económica, político y social en 2007, y especialmente a partir de 2012, se ha producido "en Cataluña una aceleración secesionista por parte de las instituciones autonómicas y de un segmento relevante de la opinión pública que ha puesto sobre el tapete cuestiones que apenas se habían suscitado ni en los debates constituyentes ni en los años de vigencia del actual sistema democrático y constitucional" (Castellà Andreu, 2016, p. 561). Desde entonces, se han producido grandes movilizaciones públicas y acciones políticas por parte de las instituciones y por parte de la ciudadanía. Dichas acciones han tenido respuesta por parte de las instituciones estatales que han impugnado y rechazado tales demandas apelando a la Constitución principalmente. Pero también ha habido una respuesta por parte de los medios de comunicación estatales y autonómicos que han posicionado el "conflicto catalán-español" como uno de los tópicos principales de sus agendas mediáticas mostrando grandes dosis de manipulación informativa (Gili Ferré, 2017) y ausencia de pluralismo (Almirón, 2018). Todo ello ha generado un conflicto político y social de grandes magnitudes. Si bien el ambiente de confrontación se da entre las instituciones catalanas y las de Madrid, y entre parte de la ciudadanía "catalana que reclama un referéndum para decidir que la Comunidad Autónoma de Cataluña pueda convertirse en una república independiente, y otro sector que quiere mantenerse dentro del Reino de España" (Serra, Ubasart González y Martí i Puig, 2018), en el momento actual se ha tornado en un conflicto social que ha trascendido las fronteras de Cataluña y en el que toda la ciudadanía española catalana o no- se ha visto implicada. 
Para contextualizar brevemente el llamado "proceso catalán" podríamos destacar los siguientes momentos clave: 1) El gobierno de la Generalitat -desde enero de 2016- es una coalición electoral llamada Junts pel Sí, formada por la unión entre Convergencia y Esquerra Republicana de Catalunya, dos partidos independentistas. 2) Este gobierno, encabezado por Carles Puigdemont, plantea un referéndum de autodeterminación para el día 1 de octubre de 2017, después de aprobar una Ley del Referéndum con el apoyo de Junts pel Sí y de la CUP (con un total de 72 votos) en el Parlamento, el día 6 de septiembre de 2017. 3) El 7 de septiembre el gobierno español declara este referéndum ilegal y el Tribunal Constitucional lo suspende de forma cautelar, al tiempo que observadores internacionales expresan que el referéndum no cumple con las garantías mínimas para una consulta de estas dimensiones. 4) La votación se celebra, de todos modos, bajo la mirada de los observadores internacionales en una jornada muy convulsa donde se producen cargas policiales sobre los ciudadanos que asisten a los colegios electorales y enfrentamientos violentos en las calles de las principales ciudades catalanas, dejando 893 heridos, según fuentes de la Generalitat. 5) Después de la consulta, el Parlamento autonómico propone una Declaración Unilateral de Independencia (DUI), ya que considera que los resultados son válidos y suficientes para poder continuar con el "proceso de independencia". 6) El Gobierno central interviene las instituciones autonómicas catalanas y activa el artículo 155 de la Constitución Española (mediante el cual puede adoptar las medidas necesarias para obligar a la comunidad autónoma al cumplimiento forzoso de las obligaciones requeridas).

\section{Objetivos, hipótesis y preguntas de investigación}

El objetivo general del presente estudio es analizar, en el contexto de la era de la postverdad y el discurso del odio en redes sociales, los mensajes de los políticos en Twitter en las inmediaciones de la votación del 1 de octubre, así como las respuestas a estos. De esta forma, se pretende estudiar el contenido de los mensajes en términos de veracidad y racionalidad, por un lado, y la reacción del resto de usuarios ante los dictados de sus representantes públicos. En este sentido, se plantean cuatro hipótesis, dos referidas a los mensajes de los políticos y dos a las respuestas a los mismos.

H1. Los mensajes de los políticos se basan en noticias o hechos falsos.

H2. Los mensajes de los políticos se fundamentan más en un juicio emocional que en una argumentación racional.

H3. Las respuestas con intención de criticar y atacar al líder político o a su mensaje son más frecuentes que aquellas que buscan el apoyo de estos.

H4. Las respuestas a los mensajes de los políticos se fundamentan más en un juicio emocional que en una argumentación racional.

Aparte de estas cuatro hipótesis, y en consonancia con el incremento del odio y la confrontación vertidos en redes sociales, cabe hacerse la siguiente pregunta de investigación:

PI1. ¿Se puede hablar de "agresión" hacia los políticos por parte de los usuarios en sus respuestas? 


\section{Metodología}

Siguiendo una metodología cuantitativa, se analizaron los mensajes difundidos a través de Twitter por diferentes representantes políticos en el contexto del referéndum por la independencia de Catalunya de 2017. En concreto, se aplicó un análisis de contenido a los tuits emitidos (descartando los retuits) los días 30 de septiembre, y 1 y 2 de octubre, por los líderes o los portavoces de los grupos parlamentarios -excluyendo al grupo mixto- tanto a nivel nacional como a nivel autonómico en dicho periodo, así como a los tres primeros mensajes de respuesta que dichos tuits recibieron -o el total en el caso de que las respuestas fueran menos de cuatro-, siguiendo un criterio cronológico. Al respecto, cabe señalar que se decidió escoger los mensajes de los políticos y no de los partidos por el cariz más personal de los primeros, a pesar de que el uso de community managers en estas cuentas es la tónica general.

En definitiva, se seleccionaron un total de 573 tuits, de los cuales 150 comprendían el total de los tuits emitidos por los líderes políticos y 423 una muestra de los 80.650 publicados por otros usuarios en respuesta a los primeros. En la tabla 1 se recoge la información relativa a los representantes políticos analizados y sus mensajes. La codificación fue llevada a cabo por dos jueces, obteniéndose un índice de fiabilidad intercodificadores tras el proceso de entrenamiento y corrección de los términos de la ficha de análisis y el libro de códigos de 0,949 según el alfa de Krippendorff (2004). Se supera así el umbral marcado por el propio Krippendorff, alcanzándose un nivel de fiabilidad bastante alto, sobre todo teniendo en cuenta el contenido temático de algunas variables. En dicha ficha se recogió, aparte de la información relativa al perfil y al número de seguidores de los usuarios emisores (tanto de los líderes políticos como de los que respondieron a estos), algunos datos generales respecto a los mensajes: número de respuestas, número de retuits y número de veces que fue marcado como favorito, hashtags utilizados, menciones a otras cuentas realizadas. Por otro lado, como se recoge a continuación, diez variables fueron especialmente relevantes para el análisis; las cinco primeras referidas a los mensajes originales y las otras cinco a las respuestas:

1. Tema principal del mensaje original: se consideró si el tuit emitido por el líder político versaba sobre el referéndum catalán o sobre otro tema diferente.

2. Función del mensaje original: se indicó el propósito del tuit emitido por el líder político según un listado de 13 categorías (actualización informativa, crítica o aprobación a la gestión del gobierno central o catalán, crítica o apoyo a la violencia policial y/o de los manifestantes, exaltación de los valores democráticos, exaltación de la Constitución española, derecho a decidir, etc.).

3. Veracidad del mensaje: se apuntó si la información vertida por el político en el tuit era verdadera, falsa o si esto no podía comprobarse.

4. Tono del mensaje original: se indicó si el mensaje se redactaba en un tono positivo, negativo o neutro. Dentro de esta última categoría también se codificaron aquellos tuits que desarrollaran un tono irónico.

5. Contenido racional o emocional del mensaje original: se marcó si el contenido del tuit era de índole racional, cuando aportaba datos comprobables, o emocional, cuando se basaba en una opinión o sentimiento que no podía ser cotejada con datos objetivos. 
6. Intención de la respuesta: se señaló si el tuit de respuesta pretendía atacar o apoyar al tuit original y/o a su emisor.

7. Argumentación de la respuesta: se indicó si se argumentaba el porqué de la postura tomada en el tuit de respuesta.

8. Tono del mensaje: se indicó si el mensaje se redactaba en un tono positivo, negativo o neutro. Dentro de esta última categoría también se codificaron aquellos tuits que desarrollaran un tono irónico.

9. Contenido racional o emocional del mensaje de respuesta: se marcó si el contenido del tuit era de racional, cuando aportaba datos comprobables, o emocional, cuando se basaba en una opinión o sentimiento que no podía ser cotejada con datos objetivos.

10. Agresión verbal y/o física: se puntualizó si el mensaje contenía algún insulto o falta hacia el político o su grupo, así como si se le/s amenazaba con algún tipo de agresión física. 


\begin{tabular}{|c|c|c|c|c|c|}
\hline Líder político & Grupo parlamentario & Ámbito parlamentario & Tuits & Respuestas & Resp (muestra) \\
\hline Mariano Rajoy & Popular en el Congreso & Congreso de los Diputados & 16 & 19481 & 48 \\
\hline Cristina Narbona & Socialista & Congreso de los Diputados & 2 & 58 & 3 \\
\hline Pedro Sánchez & Líder del PSOE. Sin escaño de diputado & & 12 & 12093 & 36 \\
\hline Pablo Iglesias & Conf. Unidos Podemos-En Comú Podem-En Marea & Congreso de los Diputados & 27 & 37759 & 81 \\
\hline Albert Rivera & Ciudadanos & Congreso de los Diputados & 9 & 2632 & 27 \\
\hline Joan Tardà & Esquerra Republicana & Congreso de los Diputados & 7 & 1875 & 21 \\
\hline Aitor Esteban & Vasco (EAJ-PNV) & Congreso de los Diputados & 3 & 6 & 3 \\
\hline Marta Rovira* & Junts pel Sí & Parlament de Catalunya & 5 & 202 & 15 \\
\hline Inés Arrimadas & Ciutadans & Parlament de Catalunya & 1 & 559 & 3 \\
\hline Miquel Iceta & Socialista & Parlament de Catalunya & 24 & 1604 & 72 \\
\hline JL Franco Rabell & Catalunya sí que es Pot & Parlament de Catalunya & 11 & 312 & 28 \\
\hline Xavier García Albiol & Partit Popular de Catalunya & Parlament de Catalunya & 16 & 3940 & 46 \\
\hline Mireia Boya & Candidatura d'Unitat Popular - Crida Constituent & Parlament de Catalunya & 17 & 129 & 40 \\
\hline
\end{tabular}

Tabla 1: Líderes políticos, ámbito y mensajes analizados.

* Se analizaron los mensajes de Marta Rovira, al no estar Lluís Corominas en Twitter. 


\begin{tabular}{|c|c|c|c|c|c|c|c|c|c|c|}
\hline \multirow{2}{*}{ Líder político } & \multirow{2}{*}{ Seguidores } & \multicolumn{3}{|l|}{ Tuits } & \multicolumn{2}{|c|}{ Favoritos } & \multicolumn{2}{|l|}{ Retuits } & \multicolumn{2}{|c|}{ Respuestas } \\
\hline & & $30 / 09 / 17$ & $01 / 10 / 17$ & $02 / 10 / 17$ & Media & SD & Media & SD & Media & SD \\
\hline Mariano Rajoy & 1.624 .111 & 0 & 13 & 3 & 1685,9 & 901,7 & 867,8 & 428,3 & 1142,6 & 643,9 \\
\hline Cristina Narbona & 19.199 & 0 & 2 & 0 & 62,5 & 82,7 & 67,5 & 87,0 & 29,0 & 41,0 \\
\hline Pedro Sánchez & 733.026 & 8 & 2 & 2 & 1072,6 & 1013,1 & 772,3 & 791,7 & 1007,8 & 1630,0 \\
\hline Pablo Iglesias & 2.255 .309 & 3 & 20 & 4 & 8599,2 & 11155,8 & 6718,0 & 9473,9 & 1398,5 & 2011,0 \\
\hline Albert Rivera & 940.316 & 6 & 3 & 0 & 2422,3 & 2501,5 & 1639,6 & 1749,1 & 292,4 & 362,9 \\
\hline Joan Tardà & 297.160 & 2 & 4 & 1 & 4067,0 & 4195,8 & 2228,9 & 2562,9 & 267,9 & 456,8 \\
\hline Aitor Esteban & 20.179 & 0 & 3 & 0 & 14,0 & 11,3 & 7,3 & 12,7 & 2,0 & 3,5 \\
\hline Marta Rovira & 146.386 & 0 & 4 & 1 & 1429,4 & 1522,2 & 1052,8 & 1380,1 & 40,4 & 44,9 \\
\hline Inés Arrimadas & 328.041 & 0 & 0 & 1 & 1720,0 & - & 941,0 & - & 559,0 & - \\
\hline Miquel Iceta & 75.506 & 12 & 5 & 7 & 151,7 & 185,5 & 130,8 & 159,6 & 66,8 & 97,2 \\
\hline JL Franco Rabell & 17.576 & 2 & 5 & 4 & 43,5 & 36,9 & 33,5 & 30,1 & 28,4 & 35,3 \\
\hline X. García Albiol & 56.987 & 6 & 5 & 5 & 521,1 & 525,0 & 394,6 & 499,0 & 246,3 & 242,0 \\
\hline Mireia Boya & 29.928 & 1 & 12 & 4 & 258,1 & 195,1 & 211,1 & 232,6 & 7,6 & 10,9 \\
\hline Total & & 40 & 78 & 32 & 2321,2 & 5714,3 & 1697,8 & 4702,2 & 529,7 & 1130,7 \\
\hline
\end{tabular}

Tabla 2: Favoritos, retuits y respuestas de los mensajes emitidos por los representantes políticos. 


\section{Resultados}

En la tabla 2 se recoge la distribución de tuits publicados por días. Por lo general, fue el día de la votación el que concentró el mayor número de mensajes (52,0\% del total), si bien hubo políticos como Albert Rivera o Miquel Iceta, que tuvieron una mayor actividad el día previo a la misma. En la tabla se recoge, asimismo, la media y desviación típica de los "favoritos", retuits y respuestas obtenidos por los mensajes de los líderes políticos analizados. Por lo general, son aquellos representantes políticos de los partidos mayoritarios que ostentan su cargo a nivel nacional los que alcanzan una mayor repercusión con sus tuits, lo cual resulta lógico teniendo en cuenta que a priori podrían alcanzar a una mayor población.

Más allá de la información recogida en la Tabla 2, cabe señalar que el 87,3\% de los tuits emitidos versaban directamente sobre el referéndum, en una proporción semejante para la mayoría de los políticos, no pudiéndose detectar diferencias significativas al respecto. En cuanto a las funciones concretas de los mensajes, destacan aquellos que perseguían la crítica a la gestión del gobierno central $(20,7 \%)$ y del gobierno catalán $(15,3 \%)$, así como aquellos que denostaban la violencia policial $(16,7 \%)$ desarrollada durante los acontecimientos del 1 de octubre. Sin embargo, esta cuestión depende tanto de los representantes políticos como de los partidos a los que pertenecen, sin establecerse diferencias significativas en cuanto a circunscripción. Así, mientras que los mensajes del Partido Popular y de Ciudadanos destacaban por criticar la gestión (e intenciones) del gobierno catalán (34,4\% y 30,0\%, respectivamente), los de Unidos Podemos y Catalunya sí que es Pot se centraban en la denuncia de la gestión del gobierno central $(47,4 \%)$ y de la violencia policial (31,6\%); dos funciones que también destacaron en Junts pel Sí. Por su parte, los intentos de crítica tanto al gobierno central como al gobierno de la Generalitat de Catalunya del grupo parlamentario socialista eran bastante similares $(23,7 \%$ y $21,1 \%)$.

Los líderes de la Generalitat han pretendido liquidar los derechos de los españoles con la violación de la ley. Son los responsables (@marianorajoy, 01/10/2017).

Convergència-ERC se quitan la careta: ni referéndum ni elecciones, solo querían dar un golpe y declarar la secesión. (@Albert_Rivera, 01/10/2017).

Si algo rompe España es que el PP y los que le sostienen en el Congreso sigan destrozando la democracia \#Rajoydimision \#Noenminombre (@Pablo_Iglesias_, 01/10/2017).

1. Recordem a tothom que estem compromesos amb la resistència pacífica. És l'estat qui exerceix la violencia (@martarovira, 01/10/2017) ${ }^{1}$.

Ni el problema de Cataluña es España ni el problema de España es Cataluña. El problema son sus malos gobernantes. (@sanchezcastejon, 30/09/2017).

En lo que respecta a la veracidad de los mensajes, el 34,0\% fueron cuantificados como verdaderos, si bien solo el 3,3\% se pudieron reconocer como falsos. El resto de los mensajes contenían, en su mayoría, opiniones por parte de los políticos, cuya veracidad o falsedad no se podía comprobar. Es preferible, por tanto, analizar el contenido racional/emocional de los tuits (Tabla 3). En este sentido, resulta interesante que el $66,0 \%$ de los mensajes destacasen por su contenido emocional, siendo esta la tónica general para la

1 "Recordemos a todos que estamos comprometidos con la resistencia pacífica. Es el estado el que ejerce la violencia" (traducción propia). 
mayoría de las agrupaciones. De hecho, a nivel de usuario, solo Miquel Iceta destaca por no seguir esta tendencia, si bien esto sucede porque muchos de sus mensajes son meros enlaces a opiniones vertidas por otros en algún periódico, sirviendo el Secretario del Partit dels Socialistes de Catalunya (PSC) como mero altavoz más allá de que en los titulares utilizados se pueda recoger cierto tono emocional.

Tabla 3: Contenido racional/emocional de los tuits (\%).

\begin{tabular}{lllll}
\hline Partido/Grupo & Racional & Emocional & Otro & Total \\
\hline Popular.../Partit Popular & 21,9 & 65,6 & 12,5 & 32 \\
Socialista & 21,1 & 34,2 & 44,7 & 38 \\
Unidos Podemos.../Catalunya sí que es Pot & 15,8 & 81,6 & 2,6 & 38 \\
Ciudadanos/Ciutadans & 10,0 & 90,0 & 0,0 & 10 \\
Esquerra Republicana & 0,0 & 71,4 & 28,6 & 7 \\
Vasco (EAJ-PNV) & 33,3 & 33,3 & 33,3 & 3 \\
Junts Pel Sí & 0,0 & 100,0 & 0,0 & 5 \\
Candidatura d'Unitat Popular... & 17,6 & 82,4 & 0,0 & 17 \\
\hline Total & 17,3 & 66,0 & 16,7 & 150 \\
\hline
\end{tabular}

Por último, en relación al tono de los mensajes, aunque no se encuentran diferencias reseñables entre los diferentes partidos, sí es cierto que los dirigentes de Unidos Podemos analizados tienen una mayor tendencia a emitir mensajes de corte negativo (65,8\%), mientras que Partido Popular $(53,1 \%)$ o Junts pel Sí $(60,0 \%)$ publican tuits con un tono más positivo. En cualquier caso, el tono de los mensajes guarda una estrecha relación con la función de los mismos, pues es lógico que aquellos tuits que buscan la crítica hacia la gestión del gobierno se redacten en negativo, mientras que aquellos otros de aprobación lo harían en positivo.

Muy orgulloso de los miles de catalanes que defendéis sin descanso la unidad de España. iGRACIAS! ES \#UnDomingoLegal (@Albiol_XG, 30/09/2017).

El Palau Robert ple de gom a gom, amb gent pacífica i compromesa amb els drets fonamentals \#CatalanReferendum (@martarovira, 01/10/2017)2.

Es urgente sacar a estos corruptos, inútiles, irresponsables e hipócritas del Gobierno. Están llevando la democracia al desastre (@Pablo_Iglesias_,01/10/2017).

La Policia Nacional no pot piular d'aquesta manera, com si fossin una força militant i no servidors públics. Molt perillosa aquesta deriva (@LluisRabell, 30/09/2017)33.

En lo que respecta a las respuestas, los 423 mensajes analizados obtuvieron una media de 21,8 favoritos $(S D=78,8), 5,1$ retuits $(S D=24,7)$ y 3,1 respuestas $(S D=9,2)$. Estos fueron emitidos por 393 usuarios únicos con una media de 1280,9 seguidores $(S D=6831,4)$. Así, del total de usuarios, solo el $46,4 \%$ podía

\footnotetext{
2 "El Palau Robert lleno hasta la bandera, con gente pacífica y comprometida con los derechos fundamentales \#CatalanReferendum" (traducción propia).

3 "La Policía Nacional no puede tuitear de este modo, como si fueran una fuerza militante y no servidores públicos. Muy peligrosa esta deriva" (traducción propia).
} 
ser identificado a través de su nombre o imagen de perfil. Asimismo, un 26,5\% tuiteaba desde Catalunya y otro 23,9\% desde otras regiones de España, mientras que un 44,5\% no aportaba datos sobre su ubicación. Más allá de los usuarios, el $65,1 \%$ de los tuits fueron redactados en castellano y el $30,4 \%$ en catalán. E $8,7 \%$ utilizaba algún hashtag y el 7,5\% hacían mención a otro usuario aparte de a aquel al que respondían. En cuanto al contenido añadido al tuit, el 9,4\% de los textos iban acompañados de una imagen, el 1,2\% de vídeo y el 2,3\% enlazaban a otra información dentro o fuera de Twitter.

En consonancia con la idea de veracidad, cabe señalar cómo frente al 19,0\% de los mensajes que sí desmentirían el mensaje original, la gran mayoría de los tuits analizados no conseguirían dicho fin, pues al fin y al cabo, como se indicó anteriormente, tampoco se puede determinar la veracidad o no de unos mensajes que, principalmente, contienen opiniones de los usuarios. Al respecto, resulta más interesante analizar la intención de dicha respuesta, en cuanto a atacar o defender al político o a su mensaje, si esta estaba o no argumentada, así como el contenido racional/emocional de la misma. En cuanto a la primera variable, el 66,3\% de los mensajes de respuesta fueron categorizados de ataque, destacando las réplicas a los mensajes de Xabier Albiol, Miquel Iceta, Pablo Iglesias y Mariano Rajoy. Al respecto, si atendemos a las organizaciones políticas, las más atacadas fueron, por orden, el Partido Popular (83,0\%), el Partido Socialista (76,6\%) y Unidos Podemos-En Comú Podem-En Marea junto a Catalunya sí que es Pot (74,3\%). En relación a la argumentación, el 74,5\% de las respuestas no estaban argumentadas. En esta línea, el 47,5\% del total de respuestas fueron ataques sin argumentación, hallándose diferencias significativas entre las dos variables (X2 $(2)=7,90, p<, 02)$. Por último, en cuanto a la posición de las respuestas en el eje racional-emocional, se incrementa la tendencia vista en los mensajes originales con un $81,5 \%$ de respuestas cuantificadas como emocionales. En esta ocasión también se hallan diferencias significativas entre las variables ataque/defensa y contenido racional/emocional (x2 (4) = 49,88, p < ,001), contabilizándose en un 57,5\% sobre el total de mensajes las respuestas que buscaban el ataque con mensajes de carga emocional.

En lo que respecta al tono de las respuestas, estas fueron, en consonancia con los datos anteriores, mayoritariamente negativas (59,5\%). Al respecto, se hallaron diferencias significativas, según el estadístico chi-cuadrado, entre la variable tono y las variables ataque/defensa ( $X 2(4)=228,81, p<, 001)$, argumentación $(X 2(2)=14,4, p<, 001)$ y razón/emoción $(X 2(4)=50,79, p<, 001)$. De esta forma, el $34,3 \%$ de las respuestas cumplían el criterio de ser un ataque sin argumentación con contenido emocional y tono negativo; un porcentaje que ascendía a 44,2\% cuando se eliminaba el tono, habida cuenta de que varios de los mensajes más que un tono negativo utilizaban un tono irónico, que se codificó como una categoría diferente.

No tens ni una gota de dignitat!! Ets fastigós!!4 (@edgarabrilfor, 02/10/2017; en respuesta al tuit del 02/10/2017 de @Albiol_XG: "Totalitarismo en estado puro. La realidad social del independentismo una vez se marchan las cámaras de TV").

Tú en la sombra, como los mayores hipócritas de la historia, así serás recordado en los libros de texto. Velencoso el invisible. Defiende a tu país valiente mediocre!!!!! (@fialeiro, 30/09/2017; en respuesta al tuit de 30/09/2017 de @sanchezcastejon: "La única victoria en Catalunya es el acuerdo y ahí nos encontrarán a los socialistas. En el acuerdo y no en la política de bloques.").

\footnotetext{
4 "No tienes ni una gota de dignidad !! Eres asqueroso !!" (traducción propia).
} 
A mí me repugna tu apoyo incondicional a Maduro y no por ello me quiero separar de España. Hecha una mano a pacificar o calla! (@CiudadanosTorr, 01/10/2017; en respuesta al tuit del 01/10/2017 de @Pablo_Iglesias_: "Porrazos, empujones, ancianas arrastradas. Lo que está haciendo el PP a nuestra democracia me repugna. Corruptos, hipócritas, inútiles").

Deja ya de vender a ESPAÑA y haz cumplir la ley, mete.en la carcel a los golpistas (@losserranosanti, 01/10/2017; en respuesta al tuit del 01/10/2017 de @marianorajoy: "Voy a comparecer en el @Congreso_Es y convocaré a las fuerzas políticas para reflexionar sobre un futuro que tenemos que afrontar juntos").

En conexión con estas últimas variables, y respecto a la relación entre mensaje original y mensaje de respuesta, se detectaron diferencias significativas entre el tono del mensaje original y el de respuesta ( $\mathrm{X} 2$ $(4)=46,01, p<, 001)$, de modo que cuando el mensaje original se torna negativo, el de respuesta también lo es. Asimismo, se encontraron también diferencias significativas entre el contenido racional/emocional del mensaje original y la intención de la respuesta $(X 2(4)=12,76, p<, 013)$, detectándose una mayor frecuencia de respuestas con intención de ataque, pero también de defensa, cuando el mensaje original tiene un componente emocional, como manifiestan los siguientes ejemplos:

Diumenge ho veurem Xavier... ets un polític mediocre ${ }^{5}$ (@statufly, 30/09/2017; en respuesta al tuit del 30/09/2017 de @Albiol_XG: "El hartazgo independentista tiene un efecto positivo. En ciudades

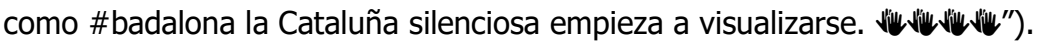

Gràcies per tot @yeyaboya, dama de civilització occitana i de nació catalana (@jarnair, 01/10/2017; en respuesta al tuit del 01/10/2017 de @yeyaboya: "Despertar a l'escola per obrir-la davant d'aquells que la volen tancar. Som imparables \#CatalanReferendum") ${ }^{6}$.

Por otra parte, en consonancia con la idea del discurso del odio que impregna las redes sociales, resulta especialmente interesante el análisis de las agresiones verbales e incluso de promesa de agresiones físicas. En esta línea, es cierto que las agresiones verbales (15,0\%) y los deseos de agredir físicamente $(1,2 \%)$ registrados no resultan reseñables desde un punto de vista cuantitativo, pero cualitativamente sí que deben tenerse en consideración. En cualquier caso, en proporción, los políticos más agredidos verbalmente fueron Aitor Esteban (33,3\%), Xabier Albiol (21,7\%) y Miquel Iceta (20,8\%), mientras que las agresiones físicas fueron dirigidas hacia Mireia Boya, Mariano Rajoy y Marta Rovira. Asimismo, no se hallaron diferencias significativas entre que el usuario sea anónimo, es decir, que no se le pueda identificar ni por el nombre ni por la fotografía de perfil, y que ataque o defienda el político o a su mensaje, o agreda de alguna forma. A continuación se recogen algunos ejemplos de agresiones de diferentes niveles de intensidad:

\footnotetext{
5 "El domingo lo veremos Xavier... eres un político mediocre" (traducción propia)

6 "Gracias por todo @yeyaboya, dama de la civilización occitana y de la nación catalana" (@jarnair, 01/10/2017; en respuesta al tuit del 01/10/2017 de @yeyaboya: "Despertar en la escuela para abrirla delante de aquellos que la quieren cerrar. Somos imparables \#CatalanReferendum") (traducción propia).
} 
Eres un sinvergüenza (@lasantalocura64, 01/10/2017; en respuesta al tuit del 01/10/2017 de @Pablo_Iglesias_: "7. El Gobierno debe detener inmediatamente la represión y permitir que los ciudadanos en Catalunya se expresen en libertad").

Tú si qeres repugnante y sin embargo ahí estás, cobrando $\mathrm{x}$ decir sandeces y hacer teatro, aparte d posicionarte del lado d los delincuentes (@jltasende, 01/10/2017; en respuesta al tuit del 01/10/2017 de @Pablo_Iglesias_: "Porrazos, empujones, ancianas arrastradas. Lo que está haciendo el PP a nuestra democracia me repugna. Corruptos, hipócritas, inútiles").

El dia que té cojan de los testículos la policia que debería defenderte como me han hecho ese día sentirás lo que has generado hoy (@Toniarbocet, 01/10/2017; en respuesta al tuit del 01/10/2017 de @marianorajoy: "No ha habido un referéndum de autodeterminación, sino una escenificación más contra la legalidad. El Estado de Derecho mantiene su vigencia"). pocas os han dado hijos de perra...os tenían q masacrar (@manuelboto, 03/10/2017; en respuesta al tuit del 01/10/2017 de @yeyaboya: "La vergonya en forma de bales de goma. Adéu @EnricMillo"7).

\section{Discusión y conclusiones}

El presente trabajo perseguía, como objetivo principal, analizar las conversaciones mantenidas entre los políticos y el resto de ciudadanos en Twitter en torno a las nociones de postverdad y discurso del odio. Para ello, se seleccionó uno de los acontecimientos transcurridos en el contexto español más reseñables del año 2017: el "referéndum" del 1 de octubre celebrado en Catalunya. En este sentido, se pretendía, por un lado, analizar la veracidad y racionalidad de los mensajes emitidos por los representantes de los partidos políticos y, por otro, el contenido y la intención de las respuestas.

La era de la postverdad puede ser entendida principalmente de dos formas: o bien como una era de la mentira (Tesich, 1992), o bien como una era donde prevalece la emoción más que la razón como forma de argumentación de los mensajes (Arrese, 2016; Boczkowski, 2016; González, 20017; Marzal \& Casero Ripollés, 2017; Urmeneta, 2017). A partir de estas dos perspectivas quedaron planteadas las dos primeras hipótesis del presente trabajo, a saber, que "los mensajes de los políticos se basan en noticias o hechos falsos" y que "los mensajes de los políticos se fundamentan más en un juicio emocional que en una argumentación racional". Al respecto, los resultados no permiten confirmar la primera de las hipótesis, al ser la gran mayoría de los mensajes opiniones cuya veracidad difícilmente puede ser comprobada. Sí quedaría validada, sin embargo, la segunda hipótesis, pues la tendencia general de los diferentes políticos era basar sus tuits en sentimientos o argumentos en los que primaba la carga emocional. Esta última cuestión también quedaba generalizada en las respuestas, cumpliéndose así la hipótesis 4: "Las respuestas a los mensajes de los políticos se fundamentan más en un juicio emocional que en una argumentación racional".

Por último, también quedaba confirmada la hipótesis 3 -"respuestas con intención de criticar y atacar al líder político o a su mensaje son más frecuentes que aquellas que buscan el apoyo de estos"-, aunque esta

\footnotetext{
7 "La vergüenza en forma de balas de goma. Adiós @EnricMillo" (traducción propia).
} 
tendencia al ataque era más notable cuando el mensaje original había sido emitido por determinados representantes políticos como Mariano Rajoy o Pablo Iglesias, en cuanto a la circunscripción nacional, y Xabier Albiol o Miquel Iceta en la autonómica. El número de respuestas de crítica y ataque encontrado entra en consonancia con la búsqueda de polémica que parece haberse vuelto frecuente en redes sociales (Herring et al., 2002; Torrijos, 2013); una polémica que podría pasar fácilmente a la ofensa y a la agresión o al odio (Montaña et al., 2013), de modo que toda suerte de debate quedaría interrumpido por el intercambio de insultos y deseos de maltrato. En esta línea, el estudio empírico pretendía responder a la siguiente pregunta de investigación: "¿Se puede hablar de 'agresión' hacia los políticos por parte de los usuarios en sus respuestas?" Con respecto a esta, aunque es cierto que cuantitativamente el porcentaje de injurias vertidas en los tuits analizados es muy bajo -con independencia de que los usuarios que las emiten puedan o no ser identificados por su nombre, imagen de perfil o descripción-, en cualquier caso no debería desdeñarse su uso, ya que forman parte de una tendencia generalizada de discursos intimidatorios y expresiones de odio en las redes sociales, donde el debate puede abandonar el razonamiento, el tono o los términos propios de un ágora democrática para reducirse a un foro de ataques, injurias e insultos basado en la emocionalidad. En definitiva, la esperanzadora visión de las redes sociales y, en concreto, de Twitter como canal para una participación más activa de la ciudadanía, donde los políticos y el resto de la sociedad podían conversar y debatir sobre diferentes cuestiones, fomentando así una democracia más real y efectiva, queda interrumpida en cuanto el interés no es ya rebatir al contrario sino interrumpir la discusión. Más aún, desde antes, cuando los mensajes -incluidos los "informativos" facts- se basan en opiniones y expresión de sentimientos más que en datos objetivos o en argumentos racionales. Esta contradicción se vuelve especialmente notable en casos como el analizado en el presente artículo, en el que uno de los problemas principales era, al menos de cara a la sociedad civil, la falta de posibilidad de diálogo y de conciliación de posturas.

\section{Referencias}

Aguilar, A. E. (2017). Los troles políticos. Realidad y Reflexión, 17(46), 67-75. doi: 10.5377/ryr.v0i46.5508 Aguirre Nieto, M. \& Zeta del Pozo, R. (2017). La verdad en la era de la posverdad. En Cetina Presuel, R., Gutiérrez Atala, F. \& Corredoira \& Alfonso, L. (Eds.) Periodismo de frontera y dignidad humana (pp. 162-180). Madrid: Universidad Complutense de Madrid.

Almirón, N. (2018). Cataluña y el pánico de las élites: el papel de los medios. Ámbitos. Revista Internacional de Comunicación, 40, 1-6.

Alterman, E. (2004). When Presidents Lie: A History of Official Deception and Its Consequences. New York: Penguin Books.

Alves, A. \& Oliveira, E. (2016). O novo ensino médio: uma análise de diálogos na era da pós-verdade. Puçá. Revista de Comunicação e Cultura da Faculdade Estácio do Pará, 2(1), 1-15.

Arrese, A. (2016). Política post-factual y sociedad post-mediática. Nuevas Tendencias, 97, 8-14.

Banks, J. (2010). Regulating hate speech online. International Review of Law, 24(3), 233-239.

Barberá, P., Jost, J. T., Nagler, J., Tucker, J. A., \& Bonneau, R. (2015). Tweeting from left to right: Is online political communication more than an echo chamber? Psychological Science, 26(10), 1531-1542. doi: $10.1177 / 0956797615594620$ 
Boczkowski, P. (2016). Las noticias falsas y el futuro del periodismo. La posverdad. Recuperado el 25 de junio de 2018, de Anfibia: http://www.revistaanfibia.com/ensayo/la-postverdad/

Buckels, E. E., Trapnell, P. D. \& Paulhus, D. L. (2014). Trolls just want to have fun. Personality and Individual Differences, 67, 97-102. doi: 10.1016/j.paid.2014.01.016

Camps, V. (2017). Posverdad, la nueva sofística. En Ibáñez Fanés, J. (Ed.), En la era de la posverdad: 14 ensayos (pp. 91-100). Barcelona: Calambur Editorial.

Casado Velarde, M. (2008). Algunas estrategias discursivas en el lenguaje periodístico de hoy. Boletín Hispánico Helvético, 12, pp. 71- 89.

Castellà Andreu, J.M. (2016). Tribunal Constitucional y proceso secesionista catalán: respuestas jurídicoconstitucionales a un conflicto político-constitucional. UNED. Teoría y Realidad Constitucional, 37, pp. 561-592.

Cebrián, M. (2009). Comunicación interactiva en los cibermedios. Comunicar, 33(17), 15-24. doi: 10.3916/c33-2009-02-001

Citron, D. \& Norton, H. (2011). Intermediaries and hate speech: Fostering digital citizenship for our information age. Boston University Law Reviews, 91, 1435-148.

Colomer, J. M. (2018). La aventurada apuesta por la independencia de Cataluña. Revista de Estudios Políticos, 179, 267-294. doi: 10.18042/cepc/rep.179.09

Coughlan, S. (12 de enero de 2017). Qué es la "posverdad", el concepto que puso de moda el "estilo Trump" en Estados Unidos. Recuperado el 25 de junio de 2018, de BBC: http://www.bbc.com/mundo/noticias-internacional-38594515

Chopra, S. (2014). The big connect: Politics in the age of social media. India: Random House.

Christensen, C. (2013). Wave-riding and hashtag-jumping. Twitter, minority 'third parties' and the 2012 US elections. Information, Communication \& Society, 16(5), 646-666. doi: 10.1080/1369118X.2013.783609

Congosto, M. L. (2015). Elecciones Europeas 2014: Viralidad de los mensajes en Twitter. Redes. Revista hispana para el análisis de redes sociales, 26(1), 23-52.

Cortina, A. (2017). Prólogo. En L. Alonso, V. Vázquez (Dirs.), Sobre la libertad de expresión y el discurso del odio (pp. 5-11). Sevilla: Athenaica.

Criado, J. I., Martínez-Fuentes, G., \& Silván, A. (2013). Twitter en España: las elecciones municipales españolas de 2011. RIPS, 12(1), 93-113.

Elías C. (2018). Fakenews, poder y periodismo en la era de la posverdad y "hechos alternativos". Ámbitos, 40. Recuperado el 25 de junio de 2018 de https://institucionales.us.es/ambitos/?p=3413

Enli, G. S. \& Skogerbø, E. (2013). Personalized campaigns in party-centred politics. Twitter and Facebook as arenas for political communication. Information, Communication \& Society, 16(5), 757-774. doi: 10.1080/1369118X.2013.782330

Fenoll, V. (2015). El trol de Internet. Estrategias de los usuarios para controlar el diálogo en los medios digitales durante el juicio de Francisco Camps. Dígitos: Revista de Comunicación Digital, 1, 179197.

Fernández Gómez, J. D., Hernández-Santaolalla, V., \& Sanz-Marcos, P. (2018). Influencers, marca personal e ideología política en Twitter. Cuadernos.Info, 42, 19-37. doi: 10.7764/cdi.42.1348 
Fernández Smith, G. (2017). Instrumentos lingüísticos de los discurso de odio en la prensa digital. Fragmentum, 50, 99-122. doi: 10.5902/2179219428800

Gallardo Paúls, B. \& Enguiz Oliver, S. (2016). Pseudopolítica: el discurso político en las redes sociales. Valencia: Universitat de València.

García-Galera, M. C. \& Valdivia, A. (2014). Prosumidores mediáticos. Cultura participativa de las audiencias y responsabilidad de los medios. Comunicar, 43(22), 10-13. doi: 10.3916/C43-2014-a2

Garimella, K., Morales, G. D. F., Gionis, A., \& Mathioudakis, M. (2018). Political discourse on social media: Echo chambers, gatekeepers, and the Price of bipartisanship. The Web Conference 2018 (WWW2018). Recuperado el 7 de diciembre de 2018, de ArXiv. https://arxiv.org/pdf/1801.01665.pdf

Gili Ferré, R. (2017). Els Mitjans de comunicació com a legitimadors o deslegitimadors d'un projecte polític per mitjà dels frames i les estructures narratives: el cas del procés català en el període 2006-2015. Tesis Doctoral inédita, Departament de Comunicació, Universitat Pompeu Fabra.

González, M. F. (2017). La posverdad en el plebiscito por la paz en Colombia. Nueva Sociedad, 269, 114126.

Gruzd, A., \& Roy, J. (2014). Investigating political polarization on Twitter: A Canadian perspective. Policy \& Internet, 6(1), 28-45. doi: 10.1002/1944-2866.POI354

Hernández-Santaolalla, V. \& Rubio-Hernández, M. M. (2017). Political fandom on Twitter: La Cueva and the Alberto Garzón supporters in the Spanish general elections of 2015 and 2016. El Profesional de la Información, 26(5), 838-849. doi: 10.1080/1369118X.2017.1284880

Herring, S., Job-Sluder, K., Scheckler, R. \& Barab, S. (2002). Searching for safety online: Managing trolling in a feminist forum. The Information Society, 18(5), 371-384. doi: 10.1080/01972240290108186

Keyes, R. The Post-Truth Era. Dishonesty and Deception in Contemporary Life. New York: St. Martin's Press.

Krijnen, T. \& Van Bauwel, S. (2015). Gender and Media. Representing, Producing, Consuming. Oxon \& Nueva York: Routledge.

Lăzăroiu, G. (2018). Post-thruth \& the journalistics ethos. En Peters, M. A., Rider, S., Hyvönen, M. \& Besley, T. (Eds.). (2018). Post-Truth, Fake News. Viral Modernity \& Higher Education (pp. 113-120). Singapore: Springer.

López Muñoz, J. M. \& Capponi, P. (2017). Los discursos intimidatorios: ¿de dónde vienen y a dónde van?, Fragmentum, 50, 9-17. doi: 10.5902/2179219431701

López Muñoz, J. M. \& Capponi, P. (2017). Los discursos intimidatorios: ¿de dónde vienen y a dónde van?, Fragmentum, 50, 9-17. doi: 10.5902/2179219431701

López-Hermida Russo, A. P. \& Fierro-Zamora, P. (2016). Campañas políticas y desafección ciudadana: aproximación desde Chile a los efectos de las actividades electorales en el proceso democrático. Palabra Clave, 19(2), 365-397. doi: 10.5294/pacla.2016.19.2.2

Manrique, J. L. (2016). Populismo y posverdad, ¿solo tendencias? Inmanencia, 5(1), 161-165.

Marcos Recio, J. C., Sánchez Vigil, J. M. \& Olivera Zaldua, M. (2017). La enorme mentira y la gran verdad de la información en tiempos de la postverdad. Scire, 23(2), 13-23.

Marzal Felici, J. \& Casero Ripollés, A. (2017). Editorial. El fotoperiodismo en la era de la posverdad. AdComunica, 13, 11-17. doi: 10.6035/2174-0992.2017.13.1

McNair, B. (2017). An introduction to Political Communication. London \& New York: Routledge. 
McNair, B. (2018). Fake news: Falsehood, Fabrication and Fantasy in Journalism. London \& New York: Routledge.

Montaña, S., González, V. \& Ariza, C. (2013). Ciberodio en los comentarios de la noticias en línea en Colombia. El caso de Piedad Córdoba. Palabra Clave, 16(3), 812-841. doi: 10.5294/pacla.2013.16.3.6

Moya Sánchez, M. \& Herrera Damas S. (2016). Cómo medir el potencial persuasivo en Twitter: propuesta metodológica. Palabra Clave, 19(3), 838-867. doi: 10.5294/pacla.2016.19.3.7

Navarro, L. (2009). Tres lustros del periodismo digital: interactividad e hipertextualidad. Comunicar, 33(17), 35-43. doi: 10.3916/c33-2009-02-003

Pariser, E. (2011). Beware online "filter bubbles". Recuperado el 6 de noviembre de 2017, de TED: https://www.ted.com/talks/eli pariser beware online filter bubbles

Poland, B. (2016). Haters. Harassment, Abuse, and Violence Online. Lincoln (NE): Potomac Books.

Pérez-Curiel, C. \& García-Gordillo, M. (2018). Política de influencia y tendencia fake en Twitter. Efectos postelectorales (21D) en el marco del Procés en Cataluña. El profesional de la información, 27(5), 1030-1040. doi: 10.3145/epi.2018.sep.07

Ramos, M., Fernández Gómez, J. D. \& Pineda, A. (2018). Follow the closing of the campaign on streaming: The use of Twitter by Spanish political parties during the 2014 European elections. New Media and Society, 20(1), 122-140. doi: 10.1177/1461444816660730

Reader, B. (2012). Free press vs. Free speech? The rhetoric of "civility" in regard to anonymous online comments. Journalism \& Mass Communication Quarterly, 89(3), 495-513. doi: $10.1177 / 1077699012447923$

Reagle, J. M., Jr. (2015). Reading the comments: likers, haters, and manipulators at the bottom of the Web. Cambridge (MA) \& London: MIT Press.

Roberts, D. (1 de abril de 2010). Post-truth politics. Recuperado el 21 de junio de 2018, de Grist: https://grist.org/article/2010-03-30-post-truth-politics

Rowbottom, J. (2012). To Rant, Vent and Converse: Protecting Low Level Digital Speech. The Cambridge Law Journal, 71(2), 355-383.

Rúas Araújo, X. \& Casero-Ripollés, A. (2018). Comunicación política en la época de la redes sociales: lo viejo y lo nuevo, y más allá. adComunica. Revista Científica de Estrategias, Tendencias e Innovación en Comunicación, 16, 21-24. doi: 10.6035/2174-0992.2018.16.2

Said-Hung, E. M., Prati, R.C. \& Cancino-Borbón, A. (2017). La orientación ideológica de los mensajes publicados en Twitter durante el 24M en España. Palabra Clave, 20(1), 213-238. doi: 10.5294/pacla.2017.20.1.10

Serra, M., Ubasart González, G. \& Martí I Puig, S. (2018). Catalonia and the Spanish triple crisis. Nueva Sociedad, 273, 22-32.

Shachaf, P. \& Hara, N. (2010). Beyond vandalism: Wikipedia trolls. Journal of Information Science, 36(3), 357-370. doi: 10.1177/0165551510365390

Sola-Morales, S. \& Flores, P. (2015). Twitter y las elecciones presidenciales 2013 en Chile. Revista Diálogos de FELAFACS, 91. Monográfico: Prácticas comunicativas y discursivas en el ciberespacio, 1-24.

Suler, J. R. \& Phillips, W. L. (2009). The bad boys of cyberspace: deviant behavior in a multimedia chat community. Cyberpsychology \& Behavior, 1(3), 275-294. doi: 10.1089/cpb.1998.1.275. 
Torrijos, P. (marzo de 2013). El troll de Internet y la paradoja del anonimato. Recuperado el 22 de septiembre de 2014, de Jot Down: http://www.jotdown.es/2013/03/el-troll-de-internet-ylaparadoja-del-anonimato/

Trejo Delarbre, R. (2017). Escepticismo democrático y medios en disputa en tiempos de la posverdad. Revista de la Asociación Española de Investigación de la Comunicación, 4(8), 2-9. doi: 10.24137/raeic.4.8.1

Urmeneta, M. (20 de febrero de 2017). Lecciones verdaderas tras los "fake news". Recuperado el 25 de junio de 2018, de Aceprensa: http://www.aceprensa.com/articles/lecciones-verdaderas-tras-lasfake-news/

Valadier, P. (2017). La posverdad, peligro para la democracia. Revista de Fomento social, 72(2), 297-304.

Vergeer, M. (2018). Incorrect, fake, and false. Journalists' perceived online source credibility and verification behavior. Observatorio (OBS*) Journal, 12(1), 37-52. doi: 10.15847/obsOBS12120181126

Vergeer, M. \& Hermans, L. (2013). Campaigning on Twitter: Microblogging and Online Social Networking as Campaign Tools in the 2010 General Elections in the Netherlands. Journal of Computer-Mediated Communication, 18, 399-419. doi: 10.1111/jcc4.12023

Vergeer, M., Hermans, L., \& Sams, S. (2011). Online social networks and micro-blogging in political campaigning: The exploration of a new campaign tool and a new campaign style. Party Politics, 19(3), 477-501. doi: 10.1177/1354068811407580

Viner, K. (12 de julio de 2016). How technology disrupted the truth. Recuperado el 28 de noviembre de 2017, de The Guardian: https://www.theguardian.com/media/2016/jul/12/how-technologydisrupted-the-truth

Waldron, J. (2012). The Harm in Hate Speech. Cambridge: Harvard University Press.

Warner, W. (2012, June). Detecting Hate Speech on the World Wide Web. Proceedings of the Workshop on Language in Social Media (LSM 2012) (pp 19-26). Montreal: Association for Computational Linguistics.

Weinstein, J. (1999). Hate Speech, Pornography, and the Radical Attack on Free Speech Doctrine. Boulder; Oxford: Westview Press.

Whillock, R. K. \& Slayden, D. (1995). Hate Speech. Thousand Oak: Sage.

Zugasti Azagra, R. \& Pérez González, J. (2015). La interacción política en Twitter: el caso de @ppopular y @ahorapodemos durante la campaña para las elecciones europeas de 2014. Ámbitos. Revista Internacional de Comunicación, 28, 1-14. http://institucional.us.es/ambitos/?p=1697 